\title{
A Microstrip Patch Antenna Design for RFID Applications in Sensor Network
}

\author{
Zeeshan Ali Haq \\ Jamia Hamdard, \\ New Delhi, India
}

\begin{abstract}
In this paper, a microstrip patch antenna design has been proposed to transmit data using ISM band. The antenna is mounted on a sensor node to be used in a sensor network for power efficiency and longevity of the sensor node. The antenna operates at $2.4 \mathrm{GHz}$ providing a high return loss, gain and directivity. The major advantage of using of microstrip patch antenna is low cost and small size which is an inherent parameter of a sensor node. In the proposed design the return loss of -46.843 and directivity of $6.5 \mathrm{dBi}$ is obtained.
\end{abstract}

\section{Keywords}

CST, ISM band, Antenna

\section{INTRODUCTION}

The major challenge in sensor node is increasing the life of the sensor network so as it may work uninterrupted for a longer time. The traditional network uses node hoping of data before it can be received at the cluster head of the sensor network and further the aggregated information from all sensors is transmitted to the sensor node for evaluation. With the help of the microstrip patch antenna, the cluster is able to include large number of sensor nodes in the cluster so as to increase the life span of the sensor node. In this paper a design of a microstrip patch antenna is presented which, due to its small size, can be easily mounted on the sensor node. The designed antenna has the advantage of small profile.

A patch antenna can be mounted on a flat surface or substrate. The substrate is provided with the ground plane which is particularly used with the monopole antenna and does not necessarily needed to be connected to the ground surface.

The micro strip patch antenna uses a thin patch of conductive material usually copper or rogers. The patch is placed on the top of dielectric substance FR-4 material. The substrate used has a good

*Work performed at Indian Institute of Information Technology-Allahabad, India

weight to strength ratio. Many techniques have been employed to reduce the size of the antenna and one of them is to use the patch antenna. We know that higher the surface area of the antenna, more will be the radiation of the antenna as required. We can achieve the same by increasing the number of slots, truncating the antenna at corners. But with increasing the number of slots is that the operating frequency of the antenna is increased but at the same time number of operating bands is also increased. So there has to be a trade-off between the operating frequency and the multi bands required.

Recently the patch antennas are being employed in great demand due to their high compactness and they being inexpensive. The patch antenna can be easily deployed and are therefore used widely in wireless sensor network where the cost. In this paper we propose a design of a patch antenna that works in the ISM (industrial-scientific-medical) band [1-4] where the compact antenna such as the proposed one is readily incorporated to reduce the size of the antenna and the cost as well.

In [9], an antenna is designed for body centric applications for health care monitoring. The return loss for the proposed design on body was resulted to be at $-16 \mathrm{~dB}$. The proposed design used a slotted semi-circle on the patch. In [10], another antenna was designed for health care monitoring at $2.54 \mathrm{GHz}$ and the return loss on body was resulted to be at $-31 \mathrm{~dB}$. The proposed antenna allowed the high mobility of the patients.

Another antenna was designed [11], for on body communication using a 1/8th of the wavelength for microstrip feed line. The antenna was designed for $2.5 \mathrm{GHz}$ and return loss was found to be at $-16 \mathrm{~dB}$.

In [12], a design uses a textile antenna at $2.5 \mathrm{GHz}$ and provided the on body return loss of $-9 \mathrm{~dB}$. It was applied towards the indoor positioning detection and GPS and GNSS

\section{ANTENNA DESIGN}

The proposed antenna design is shown in figure below. The substrate used is the FR4 which has a dielectric constant of 4.3 with width equal to $25.4 \mathrm{~mm}$, length equal to $20.06 \mathrm{~mm}$ and height equals to $1.6 \mathrm{~mm}$ [5].

Table: dimensions of Proposed design

\begin{tabular}{|r|l|l|}
\hline S.No. & Parameter & Dimensions \\
\hline 1. & Operating frequency & $2.4 \mathrm{GHz}$ \\
\hline 2. & Length of substrate & $45 \mathrm{~mm}$ \\
\hline 3. & Width of substrate & $35 \mathrm{~mm}$ \\
\hline 4. & Length of patch & $20.06 \mathrm{~mm}$ \\
\hline 5. & Width of patch & $25.4 \mathrm{~mm}$ \\
\hline 6. & Height of patch & $1.6 \mathrm{~mm}$ \\
\hline 7. & $\begin{array}{l}\text { Length of microstrip feed } \\
\text { line }\end{array}$ & $21.42 \mathrm{~mm}$ \\
\hline 8. & Length of vertical slot & $1 \mathrm{~mm}$ \\
\hline 9. & Width of vertical slot & $8.46 \mathrm{~mm}$ \\
\hline 10 & Length of horizontal slot & $6.58 \mathrm{~mm}$ \\
\hline 11 & Width of horizontal slot & $1.27 \mathrm{~mm}$ \\
\hline
\end{tabular}

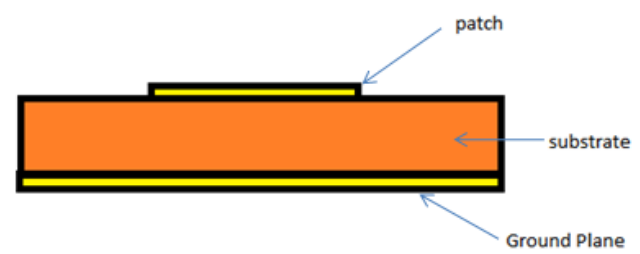

Fig 1: side view of the antenna 
On the back side of the substrate is the ground plane which is main element of a ground-plane antenna is almost always oriented vertically. This result in transmission of, and optimum response to, vertically polarized wireless signals. When the base of the antenna is placed at least 1/4 wavelength above the ground or other conducting surface, the radials behave as a near-perfect ground system for an electromagnetic field, and the antenna is highly efficient. It works equally well in all horizontal directions. The size of the antenna patch is given by the following formula by using the knowledge in which band the patch antenna is supposed to work [6].

$$
W=\frac{C}{2 f_{0} \sqrt{\frac{\epsilon_{r}+1}{2}}}
$$

Where $\mathrm{W}$ is the width of the patch, $\mathrm{C}$ is the speed of light, $\mathrm{f}_{0}$ is the operating frequency, $\varepsilon_{\mathrm{r}}$ is the dielectric constant.

The effective length of the patch is given by the following equation,

$$
L_{e f f}=\frac{C}{2 f_{0} \sqrt{\epsilon_{\text {reff }}}}=L+2 \Delta L
$$

Where $\varepsilon_{\text {reff }}$ is the effective dielectric constant

And

$$
\epsilon_{\text {reff }}=\frac{\epsilon_{r}+1}{2}+\frac{\epsilon_{r}-1}{2}\left[1+\frac{12 h}{w}\right]^{-1 / 2}
$$

Where $h$ is the height of the substrate plane.

For the operating frequency of $2.4 \mathrm{GHz}$ we found the width to be $3.8 \mathrm{~cm}$ and effective length, Leff, to be $2.89 \mathrm{~cm}$. no to increase the amount of gain and directivity of the microstrip patch antenna, in introduce the horizontal and vertical slots at the edge of the antenna as shown in the figure below.

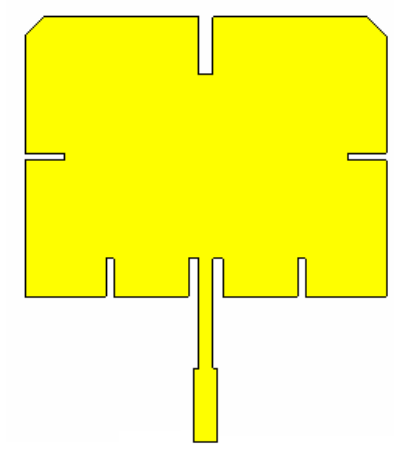

Fig 2: Design of a microstrip patch antenna

\section{RESULT AND DISCUSSION}

The proposed antenna has been simulated using CST (constant Strain Triangle) which is used to calculate the return loss, gain, the standing wave ratio and the directivity of the proposed patch antenna. The S11 parameter gives the return loss of the antenna in the required frequency band [7]. The return loss of the given antenna is simulated and is shown below in the figure.

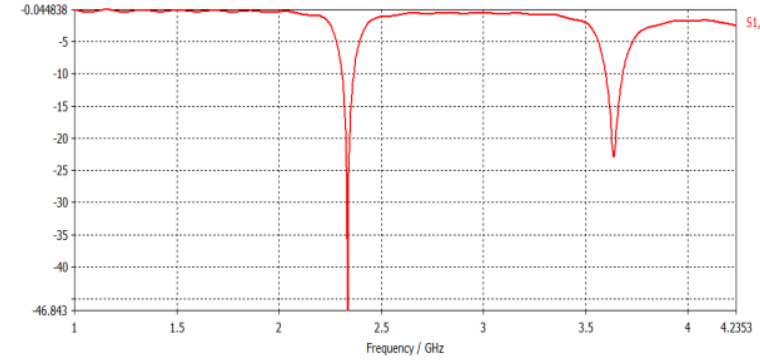

Fig 3: return loss

Here we see that the peak return loss for the antenna is obtained at $2.4 \mathrm{GHZ}$ and gives the return loss of $-46.843 \mathrm{~dB}$. Here we also observe that as we increase the frequency of operation some more band of operating frequencies are obtained at higher frequencies giving the return loss of -22.5 $\mathrm{dB}$. Hence it is advantageous to use the antenna in these frequency ranges.

The next parameter of this patch antenna observed is the gain of the antenna. The term Antenna Gain describes how much power is transmitted in the direction of peak radiation to that of an isotropic source. Antenna gain is more commonly quoted in a real antenna's specification sheet because it takes into account the actual losses that occur.

Antenna Gain is sometimes discussed as a function of angle, but when a single number is quoted the gain is the 'peak gain' over all directions $[8,2]$. Antenna Gain (G) can be related to directivity (D) by:

$$
G=\epsilon_{\text {reff }} D
$$

Where $\mathrm{G}$ is the gain and $\mathrm{D}$ is the directivity.

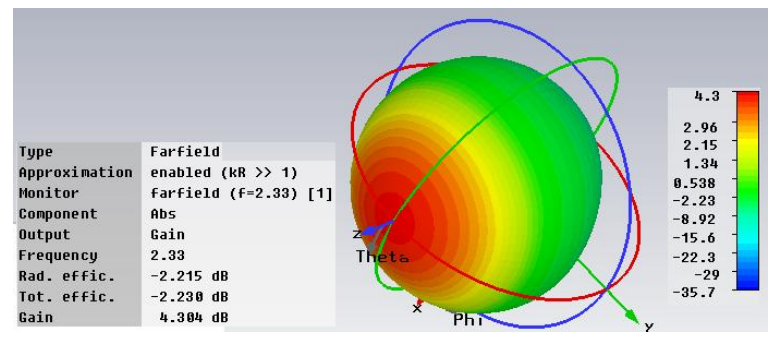

Fig 4: Gain of the proposed antenna in 3D plot

The simulated result of the antenna shows that the gain of the antenna is $4.384 \mathrm{dBi}$ and the plot in the $2 \mathrm{D}$ shows the dipole nature of the antenna.

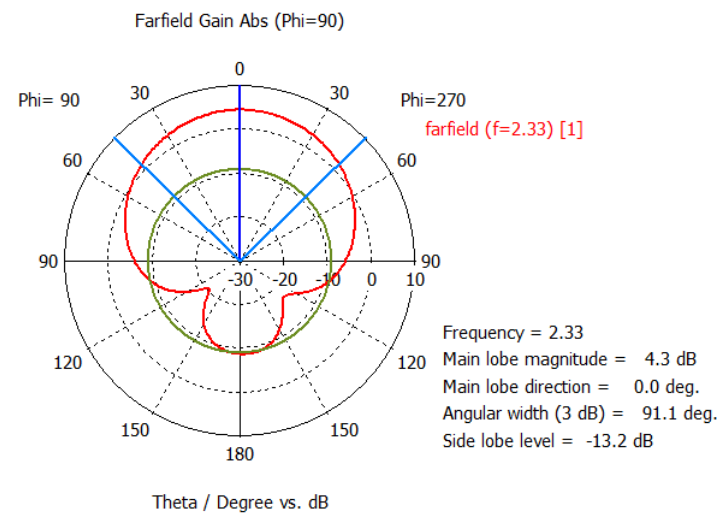

Fig 5: Gain of the antenna in 2D plot

Directivity is a fundamental antenna parameter. It is a measure of how 'directional' an antenna's radiation pattern is. An 
antenna that radiates equally in all directions would have effectively zero directionality, and the directivity of this type of antenna would be 1 (or $0 \mathrm{db}$ ).

The obtained directivity of the antenna is shown below in figure obtained after the simulation,

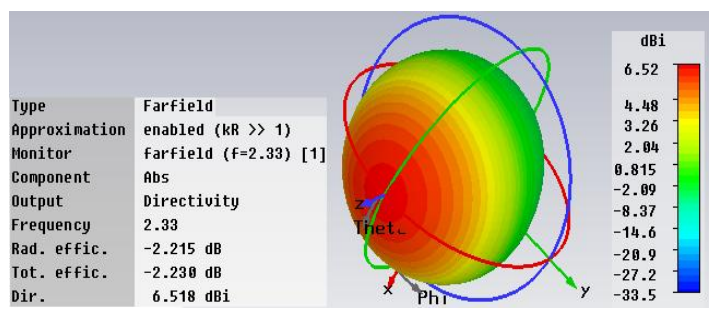

Fig 6: Directivity of the proposed antenna

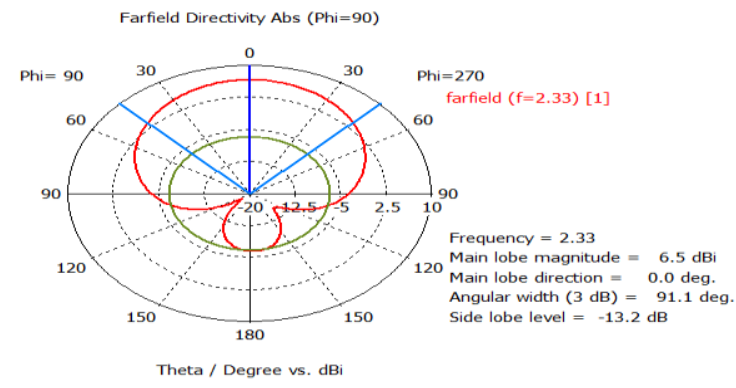

Fig 7: Gain of the antenna in 2D plot

The directivity obtained from the simulation of the antenna is recorded as $6.5 \mathrm{dBi}$.

\section{CONCLUSION}

The proposed antenna has been simulated with the ISM band in consideration. We can use this antenna in the in large medical wireless network where the size of the antenna matters a lot. It can be efficiently deployed in the wireless scenario for remote monitoring of the ageing and chronic patients so that they can independently live their life without much ado.

Since the cost is also cheap it can be implemented to the middle class and the lower class of the society for providing the improved standard of living.

\section{ACKNOWLEDGMENT}

The present work was conducted at the Indian Institute of Information Technology-Allahabad (IIIT-A). The author is thankful to Professor Shekhar Verma, IIIT-A (HODInformation Technology and Chairman of Network Committee) for his valuable guidance. Also the author is thankful to Prof. Zainul A. Jafery, Dept of Electrical Engineering, Jamia Millia Islami, New Delhi, India for his constant inputs and guidance

\section{REFERENCES}

[1] Vidya, J.S.; Shrivastava, P.; Susila, M.; Rao, T.R., "Ultra wide band Twin Eleven slot patch antenna for bandwidth enhancement," Communications and Signal Processing (ICCSP), 2013 International Conference on , vol., no., pp.92,95, 3-5 April 2013
[2] Masood, R.; Ali Mohsin, S., "Robust patch-antenna for wearable WLAN applications," Antenna Technology and Applied Electromagnetics (ANTEM), 2012 15th International Symposium on , vol., no., pp.1,5, 25-28 June 2012

[3] RongLin Li; DeJean, G.; Tentzeris, M.M.; Laskar, J., "Development and analysis of a folded shorted-patch antenna with reduced size," Antennas and Propagation, IEEE Transactions on , vol.52, no.2, pp.555,562, Feb. 2004

[4] Singh, C.; Gangwar, R. P S, "Design and analysis of a compact low cost patch antenna for different wireless operations," Emerging Trends in Networks and Computer Communications (ETNCC), 2011 International Conference on , vol., no., pp.18,22, 22-24 April 2011

[5] Singh, V.K.; Ali, Z.; Singh, A.K.; Ayub, S., "Dual Band Microstrip Antenna for UMTS/WLAN/WIMAX Applications," Communication Systems and Network Technologies (CSNT), 2013 International Conference on , vol., no., pp.47,50, 6-8 April 2013

[6] Shaikh, T.; Khan, R., "Design of microstrip patch antenna for wireless communication," Information and Communication Technologies (WICT), 2011 World Congress on , vol., no., pp.1144,1149, 11-14 Dec. 2011

[7] Ranjan, P.; Kishore, N.; Singh, I.; Tripathi, V.S., "Inverted $\mathrm{Z}$ and circular slot patch antenna for WLAN and wimax," Power, Control and Embedded Systems (ICPCES), 2012 2nd International Conference on , vol., no., pp.1,5, 17-19 Dec. 2012

[8] Rojansky, Vladimir; Winebrand, M., "Enhanced Gain Patch Antennas at Millimeter Waves," Microwave Conference, 1997. 27th European , vol.1, no., pp.567,572, 8-12 Sept. 1997

[9] Yeboah-Akowuah, Bright, Panagiotis Kosmas, and Yifan Chen. "A low profile microstrip patch antenna for bodycentric communications at $2.45 \mathrm{GHz}$ band." 2015 9th European Conference on Antennas and Propagation (EuCAP). IEEE, 2015.

[10] Agneessens, Sam, et al. "On-body wearable repeater as a data link relay for in-body wireless implants." IEEE Antennas and Wireless Propagation Letters 11 (2012): 1714-1717.

[11] Choi, Sehwan, and Hojun Lee. "Dual shorted microstrip patch antenna for on-body systems." 2015 IEEE International Symposium on Antennas and Propagation \& USNC/URSI National Radio Science Meeting. IEEE, 2015.

[12] Elliot, P. G., et al. "E-textile microstrip patch antennas for GPS." Position Location and Navigation Symposium (PLANS), 2012 IEEE/ION. IEEE, 2012. 